\title{
Neurological deterioration after laminectomy for spondylotic cervical myeloradiculopathy: the putative role of spinal cord ischaemia
}

\author{
GEORGE R CYBULSKI,* CHARLES M D’ANGELO $\dagger$ \\ From the Department of Neurosurgery, Cook County Hospital, ${ }^{*}$ and Rush-Presbyterian St Luke's Medical \\ Center, $†$ Chicago, Illinois, USA
}

SUMMARY Most cases of neurological deterioration after laminectomy for cervical radiculomyelopathy occur several weeks to months postoperatively, except when there has been direct trauma to the spinal cord or nerve roots during surgery. Four patients are described who developed episodes of neurological deterioration during the postoperative recovery period that could not be attributed to direct intraoperative trauma nor to epidural haematoma or instability of the cervical spine as a consequence of laminectomy. Following laminectomy for cervical radiculomyelopathy four patients were unchanged neurologically from their pre-operative examinations, but as they were raised into the upright position for the first time following surgery focal neurological deficits referrable to the spinal cord developed. Hypotension was present in all four cases during these episodes and three of the four patients had residual central cervical cord syndromes. These cases represent the first reported instances of spinal cord ischaemia occurring with post-operative hypotensive episodes after decompression for cervical spondylosis.

A number of possible causes for neurological deterioration after laminectomy for cervical spondylosis have been suggested. These include trauma or manipulation of the spinal cord during surgery, production of a kyphotic deformity secondary to instability caused by laminectomy, and posterior compression from scar tissue. ${ }^{1-3}$ Aside from spinal cord or nerve root injury directly during the laminectomy most of the other instances of neurological deterioration occur weeks to months following surgery.

We have observed the rapid development of neurological deficits in four patients in the postoperative period after laminectomy for cervical radiculomyelopathy. These deficits could not be attributed to surgical trauma or to compressive epidural

Address for reprint requests: George R Cybulski, MD, Department of Neurosurgery, Cook County Hospital, 1835 West Harrison Street, Chicago, Illinois 60612, USA.

Received 11 September 1987 and in revised form 7 December 1987. Accepted 24 December 1987 postoperative haematomas or spine dislocation. Because of the nature of the deficits and the exclusion of traumatic or compressive causes we infer that the spinal cord injury occurred through ischaemia.

\section{Case 1}

A 68 year old man presented with a 6 month history of progressive right arm weakness and paraesthesia of the tips of the fingers of the right hand. Examination revealed $3 / 5$ biceps strength, $3 / 5$ triceps strength, and $3 / 5$ hand intrinsic weakness, decreased pin sensation in the right $\mathrm{C} 5, \mathrm{C} 6, \mathrm{C7}$ and $\mathrm{C} 8$ dermatomes and increased deep tendon reflexes in the right arm. The patient walked with a wide-based gait and had a Babinski sign on the right. After a myelogram demonstrated prominent midline spondylotic bars at $\mathrm{C} 4, \mathrm{C5}$, and C6 with stenosis, a C3 to C6 laminectomy was performed. On the first postoperative day, shortly after the patient had been raised into the sitting position, a hypotensive episode occurred with the blood pressure dropping to $60 \mathrm{~mm} \mathrm{Hg}$ systolic. After the blood pressure was restored, examination showed severe bilateral $1-2 / 5$ arm weakness and $4 / 5$ leg weakness with bilateral Babinski signs and hyperreflexia.

Case 2

A 61 year old women presented with a 2 year history of 
right shoulder and arm pain. Examination revealed decreased right triceps and biceps strength to $4 / 5$ and diminished right biceps reflex as well as wide based gait. A computed tomographic scan of the cervical spine demonstrated significant bony ridges at the C4-5 and C5-6 interspace level with stenosis of the canal. A C4 to C6 laminectomy was performed. On the first postoperative day, the patient experienced a hypotensive episode with blood pressure dropping to $50 \mathrm{~mm} \mathrm{Hg}$ systolic after she was being raised into the sitting position. After the blood pressure was restored, she was noted to be markedly weak in the upper extremities to $2 / 5$ distally and $3 / 5$ proximally. She also complained of paraesthesia in her lower extremities.

Case 3

A 33 year old man with a congenital abnormality of the cervical spine (fused $\mathrm{C} 3,4,5$ vertebral bodies) presented with a 6 month complaint of worsening "cramping" sensation of the right shoulder and upper arm. Examination demonstrated 4/5 right shoulder abduction and arm flexion and an absent right brachioradialis reflex. A cervical myelogram showed a stenotic cervical spinal canal and a nerve root filling defect on the right at $\mathrm{C} 6-7$. The following day, a $\mathrm{Cl}$ to C7 laminectomy was performed. On the third postoperative day, after being placed upright in a chair for the first time since surgery, the patient began complaining of shortness of breath and inability to move. He was noted to be using accessory muscles for breathing and had a flaccid quadriparesis. Systemic blood pressure at this time was $60 \mathrm{~mm} \mathrm{Hg}$ systolic. He was immediately placed in the Trendelenberg position and had slow return of motor function over several minutes as blood pressure was restored to normal.

\section{Case 4}

A 73 year old man had a 1 year history of unsteadiness of gait, lower extremity weakness, and paraesthesia of the upper extremities. Examination demonstrated spastic paraparesis with lower extremity hyperreflexia and bilateral Babinski signs. A myelogram via a $\mathrm{Cl}-2$ puncture showed a complete block to flow of contrast material at $\mathrm{C} 4-5$ and a $\mathrm{C} 4$ to $\mathrm{C} 7$ laminectomy was performed. On the second postoperative day, after being raised into the sitting position, the patient had a hypotensive episode with blood pressure dropping to $50 \mathrm{~mm} \mathrm{Hg}$ systolic. After resuscitation, he was found to have a flaccid quadriparesis with the arms more affected than the legs and bilateral Babinski signs.

\section{Discussion}

Four patients incurred focal spinal cord injury in association with discreet postoperative hypotensive episodes after decompression for spondylotic myeloradiculopathy. The possible aetiology of ischaemia in the pathogenesis of postoperative neurological deterioration after laminectomy for spondylotic cervical myelopathy or radiculopathy is suggested because these patients were unchanged neurologically for more than 24 hours after surgery, and following their deterioration mechanical causes of spinal cord compression such as dislocation and epidural haematoma formation were excluded by means of lateral flexion and extension cervical radiographs and computed tomography of the cervical spine in all cases. Furthermore, all patients also had stable blood pres- sure and pulse measurements for the time period preceding the hypotensive events.

Unfortunately, spinal cord ischaemia as a cause of deterioration after laminectomy is almost impossible to prove clinically (J Hoff, personal communication), and therefore remains a diagnosis of exclusion. Three of these patients had persistent neurological deficits such as those seen with central spinal cord injury. The acute cervical cord syndrome as described by Schneider et $\mathrm{ll}^{4}$ occurred in the setting of a hyperextension injury imposed upon patients with a preexisting cervical spondylosis. The associated neurological damage occurs in end fields of spinal cord perfusion (the central gray matter) with loss of motor function in the more medial neuronal groups of the upper extremities and relative sparing of the lower extremity motor function with variable sensory loss below the level of the pathology. ${ }^{45}$ Similar vulnerability of the spinal cord has been noted following cardiac arrest and resuscitation. ${ }^{67}$

On this basis, it is postulated that all of our patients developed symptoms of spinal cord ischaemia when a drop in perfusion pressure was superimposed on a spinal cord blood supply already compromised by the osteophytic process of cervical myelopathy causing infarction in the watershed areas of the spinal cord. In addition, the presence of generalised arteriosclerosis contributes to a higher degree of vulnerability of the spinal cord to ischaemia. ${ }^{8}$ The three patients from our group who retained a neurological deficit were elderly and had a prior history of hypertension or signs of arteriosclerosis.

The authors thank Dr Julian T Hoff for his review of the manuscript and Mrs Ernestine Daniels for typing it.

\section{References}

1 Bohlman HH. Cervical spondylosis with moderate to severe myelopathy. A report of seventeen cases treated by Robinson anterior cervical discectomy and fusion. Spine 1977;2:151-62.

2 Crandall PH, Gregorius FK. Long-term follow up of surgical treatment of cervical spondylotis mylopathy. Spine 1977;2:139-46.

3 Yonenobu K, Okada K, Fuji T, Fujiwara K, Yamashita $\mathrm{K}$, Ono K. Causes of neurologic deterioration following surgical treatment of cervical myelopathy. Spine 1986;11:818-23.

4 Schneider RC, Cherry G, Dantek H. The syndrome of acute central cervical spinal cord injury. $J$ Neurosurg 1954;11:546-77.

5 Brodkey JS, Miller CF, Harmody RM. The syndrome of acute central cervical spinal cord injury revisited. Surg Neurol 1980;14:251-75.

6 Gilles FH, Nag D. Vulnerability of human spinal cord in transient cardiac arrest. Neurology 1971;21:833-9.

7 Silver JR, Buxton PH. Spinal stroke. Brain 1974; 97:546-77

8 Jellinger K. Spinal cord arteriosclerosis and progressive vascular myelopathy. J Neurol Neurosurg Psychiatry 1967;30: 195-206. 